\title{
João Rodrigues de Castelo Branco, o Médico Amato Lusitano (1511-1568)
}

\author{
João Rodrigues de Castelo Branco, \\ Portuguese Physician Amato Lusitano (1511-1568)
}

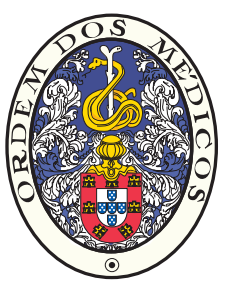

\author{
Amélia RICON FERRAZ $Z^{1,2}$ \\ Acta Med Port 2013 Sep-Oct;26(5):493-495
}

Palavras-chave: História do Século XVI; Portugal.

Keywords: History, 16th Century; Portugal.

João Rodrigues nasceu em 1511 na vila de Castelo Branco num período glorioso da nossa história. Longe de Portugal viria a adotar o nome João Rodrigues de Castelo Branco e, mais tarde, Amato Lusitano, com que se celebrizou. Descendia de uma família hebraica, responsável pela transmissão das crenças e das práticas religiosas que assumiu no período final da sua existência. ${ }^{1-4}$

Os seus primeiros estudos efetuaram-se em Portugal, que ampliou em Salamanca, numa espécie de colégio com a invocação de Santa Maria da Veiga, o conciliário dos estudantes portugueses, onde teve como Professores Pintiano, Pontano, Olivares e Alderete e onde conviveu com Luís Nunes, Cristóvão Orosco e André Laguna, personalidades notáveis da Medicina do tempo. Aí aperfeiçoou os conhecimentos de latim, grego, hebraico e árabe e estudou música e matemática. Concluído o Bacharelato em Artes familiarizou-se com a filosofia aristotélica, a ética, a metafísica e a medicina. Após o curso médico ficou responsável por duas enfermarias nos Hospitais de Santa Cruz e Santa Maria a Branca. ${ }^{1-3}$

Em 1529, regressou a Portugal, tendo realizado inúmeras incursões pelo território português e exercido clínica durante cinco anos. Conjeturam-se se os motivos reais que levaram Amato a partir foram de ordem religiosa ou política, dada a sua ascendência familiar hebraica, ou se se inscreveram na vontade inconformada de explorar o desconhecido, fonte inesgotável de saber e de oportunidades, apanágio do homem do Renascimento. ${ }^{2-4}$

Viveu sucessivamente em Antuérpia, Ferrara, Veneza, Ancona, Roma, Pesaro, Ragusa e Salónica embora visitasse e permanecesse durante curtos espaços de tempo noutros locais. Por onde passou, conviveu com as maiores sumidades dos diferentes ramos do saber e pautou-se por ser médico de papas, príncipes, embaixadores e outras personalidades de destaque nessas paragens. O seu valor foi reconhecido em vida. ${ }^{5,6}$ Nos rostos das obras Historia Plantarum Universalis (1540) de J. Baühinus e De Humani Corporis Fabrica (1543) de Andre Vesalius está representada a figura de Amato. ${ }^{7}$ A partida de Ancona deveu-se à perseguição que the foi instaurada pelos agentes do Papa
Paulo IV (1476-1556), pontífice muito rigoroso na perseguição aos Judeus. Na fuga inesperada perdeu bens e dois dos seus escritos, a $5 .^{\text {a }}$ Centúria, que reencontrou ulteriormente, e um Commentario sobre a $4 .^{a}$ Fen do Livro primeiro d'Avicena. É provável que a saída de Ragusa se devesse à publicação do libelo Apologia adversus Amatum Lusitanum (1558) de Mattiolo, onde o médico português era acusado de judaizar. ${ }^{3,4}$

Amato Lusitano foi pioneiro da tradição anatómica nacional e o primeiro professor português de Anatomia em universidade estrangeira. Fundamentalmente, em Ferrara, próximo do professor de Anatomia João Baptista Canano, pôde dedicar-se com profundidade a estes estudos. Nos seus escritos afirma ter dissecado animais e numerosos corpos humanos com o objetivo de conhecer a distribuição e a morfologia dos diferentes órgãos. Das autópsias cadavéricas que realizou recolheu importantes conhecimentos anatomopatológicos, alguns em clara oposição ao saber contemporâneo. Identificou várias situações clínicas teratológicas e de dismorfia que, de forma metódica, analisou. Em 1547, Amato Lusitano descobriu as válvulas das veias, na sequência de inúmeras experiências realizadas em animais e em cadáveres humanos, e demonstra-o publicamente (1. ${ }^{a}$ Centúria, Cura 52). Foi um contributo notável para o conhecimento da fisiologia da circulação sanguínea. ${ }^{3-5}$

Nos seus estudos de Farmacologia e Terapêutica desenvolveu importantes investigações no reino vegetal, um interesse transversal a todo o seu percurso de vida. A Casa da Índia em Lisboa, o jardim dos frades franciscanos em Antuérpia, e o horto de Marcos Pio em Ferrara foram alguns dos locais onde, pela abundância e variedade de plantas, reuniu preciosas informações para os seus trabalhos. Na segunda cidade, publicou a sua primeira obra, Index Dioscoridis (1536) com o nome de João Rodrigues de Castelo Branco, um comentário aos primeiros livros desse padre-mestre grego de Matéria Médica (séc. I d.C) e uma compilação das produções indígenas portuguesas. Aí fez referência aos recentes trabalhos de Mattiolo, Leoniceno, Laguna, Brasavola, Ruellio, entre os principais. Foi

1. Departamento de História da Medicina. Faculdade de Medicina da Universidade do Porto. Porto. Portugal.

2. Museu de História da Medicina "Maximiano Lemos". Porto. Portugal.

Recebido: 19 de Outubro de 2012 - Aceite: 05 de Maio de 2013 | Copyright $\odot$ Ordem dos Médicos 2013 


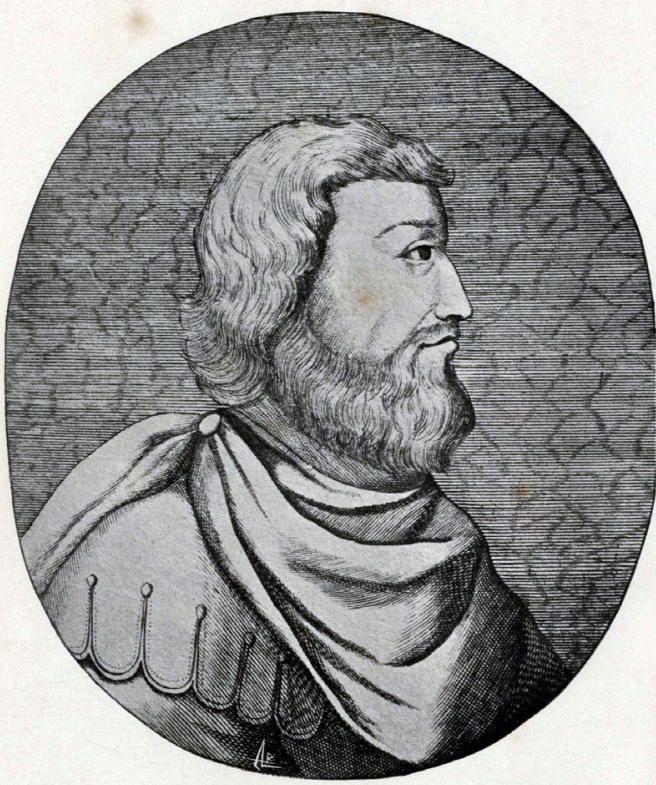

A.MAJUS LUSJJANUS

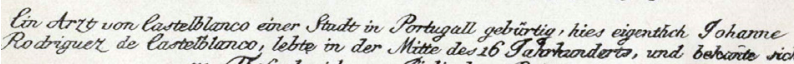
re Thefolonich ver Ristis here Retigion.

Figura 1 - Retrato de Amato Lusitano. Reprodução de uma gravura alemã publicada, pela primeira vez, pelo Professor Maximiano Lemos (1860-1923) na monografia que the dedicou em 1907. O original pertenceu ao bibliófilo portugês Anibal Fernandes Tomás.

um conhecedor apurado dos produtos transportados pelos portugueses das costas africanas, do Índico e do Extremo Oriente. Teve o privilégio de ser o primeiro a descrever os simples indiânicos, diretamente relacionados com a terapêutica médica do tempo. ${ }^{3-5}$

Amato Lusitano publicou sete Centuriae Curationum Medicinalium, um conjunto de setecentas curas médicas, cem em cada centúria. A primeira, data de 1551, em Florença e a última, de 1568, em Salónica.

Na globalidade, a obra reúne um número avultado de casos clínicos de patologia médica e cirúrgica relativa aos diferentes aparelhos e sistemas, que se revestem de um interesse médico-histórico extraordinário..$^{6,8.9}$ Amato conhecia os textos médicos de autores greco-romanos e árabes e dominava as obras dos seus contemporâneos hispânicos, italianos, franceses, teutónicos e de língua turca. $\mathrm{O}$ seu saber advinha-Ihe das extensas e variadas leituras, do convívio que privava com as personalidades mais cultas da época, e da observação e estudo de um mundo novo que constantemente o surpreendia. Teve a preocupação constante de nos casos clínicos apresentados referir a identidade do doente, a sua naturalidade e residência, a atividade laboral, o temperamento e de descrever todas as ocorrências diárias do curso das doenças, principalmente nos dias críticos. No domínio da Patologia Médica foi pioneiro na descrição da alopécia sifilítica e, descreveu pela primeira vez a introdução da raiz dos chinas em Portugal e na Europa pelo navegador português Vicente Gil de Tristão. Nos casos clínicos de Patologia Cirúrgica abundam as referências à prática de pequenas cirurgias e de algumas cirurgias maiores, nomeadamente uma variante de uretrotomia externa, de herniorrafia, a amputação dos membros e da mama, e a embriotomia. Amato foi um vulgarizador do tratamento dos apertos da uretra pelo método das velinhas, um saber transmitido por Alderete, seu professor na Universidade de Salamanca. Idealizou e mandou produzir uma placa em ouro para servir de prótese palatina numa situação clínica de ulceração sifilítica. ${ }^{2-5} \mathrm{~A}$ leitura das Centuriae permite conhecer os costumes e as tradições dos diferentes povos com quem conviveu. ${ }^{4-6,9}$

Amato Lusitano foi ainda pioneiro da escola portuguesa de Deontologia profissional médica. Em todos os seus textos clínicos inscreveu regras morais de conduta e chegou a elaborar, em 1559, em Salónica, o seu Juramento ou Julgamento, incluído na $7 .^{a}$ das suas Centuriae. Exerceu uma atividade clínica incorrupta, sem discriminação de raças, crenças ou estatutos sociais, sempre parcimonioso nas prescrições e nos honorários. No início da $1 .{ }^{a}$ Centúria descreveu os atributos que deviam possuir o médico e o doente e expôs a teoria das crises e dos dias críticos, o fundamento do prognóstico médico. ${ }^{5,10}$

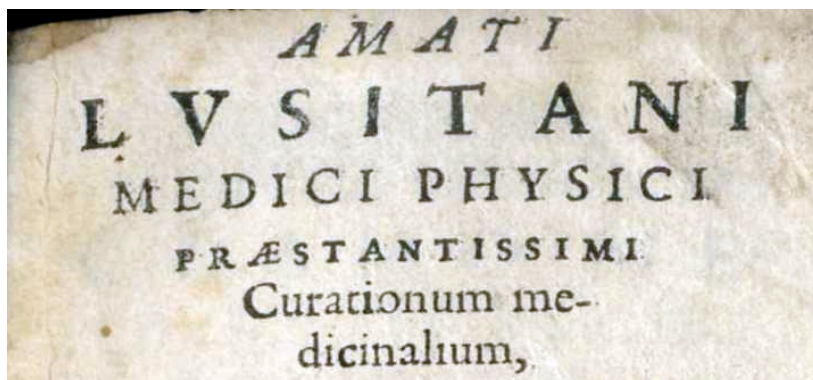

CENTVRIAE II. PRIORES.
Qubus premittitur Commentatio de introitu. medici ad egrotantem, de Criji, 6 diebus Decretorits.

Cum I N I C E rerum memorabilium copiofitsimo.

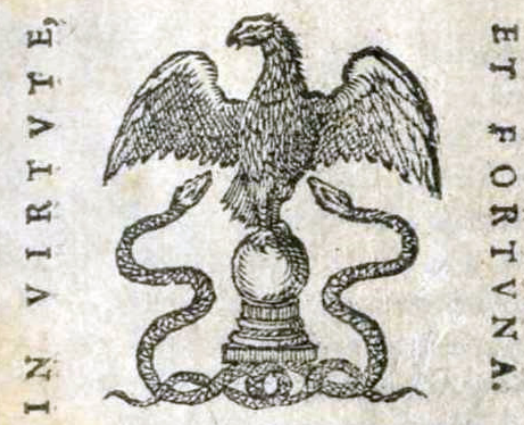

L $V D V N I$,

\section{ApudGulielinum Rouillium.}

\section{D. $L X X X$,}

Figura 2 - Rosto da Centuriae II (1580) de Amato Lusitano. Museu de História da Medicina "Maximiano Lemos" da Faculdade de Medicina da Universidade Porto. 
Foi um escritor e tratadista brilhante que não aspirava a qualquer honra, somente a vontade de contribuir para a saúde dos povos. O Index Dioscorides e as Ennarationes são obras que atestam o saber do autor enquanto naturalista. As Centuriae são um documento magistral dos conhecimentos e da prática médica do Renascimento, protagonizada por um português. Foram identificadas sessenta e três edições completas dos seus escritos, além de outras parcelares: a edição única do Index Dioscorides (1536), onze edições das Ennarrationes (1553-1577) e cinquenta e uma das Centuriae (1551-1654). ${ }^{6,11}$ Por iniciativa da Faculdade de Ciências Médicas da Universidade Nova de Lisboa, em 1980, deu ao prelo a tradução portuguesa das Centuriae, trabalho da autoria de Firmino Crespo. Em 2010, esta edição foi reeditada pela Ordem dos Médicos.

\section{REFERÊNCIAS}

1. Dias JL, compilador. Homenagem ao Doutor João Rodrigues de Castelo Branco. Castelo Branco: Câmara Municipal; 1955.

2. Jorge RA. Amato Lusitano: comentos à sua vida, obra e época: ciclo peninsular. $1^{\mathrm{a}}$ ed. Lisboa: Editorial Minerva. [1936?].

3. Lemos M. Amato Lusitano: a sua vida e a sua obra. Porto: Eduardo Tavares Martins; 1907.

4. História da Medicina em Portugal: doutrinas e instituições. $2^{\mathrm{a}}$ ed. Lisboa: Publicações Don Quixote/Ordem dos Médicos; 1991.

5. Correia M, Guerra M, Leibowitz, Pina L, Meneses M, Dias L, et al. IV Centenário de João Rodrigues de Castelo Branco - Amato Lusitano. Castelo Branco: Estudos de Castelo Branco; 1968.
O mais notável médico lusitano do século XVI, apôs uma vida de dedicação à ciência, e em particular à Medicina, sucumbiu no cumprimento do seu dever profissional durante uma epidemia de peste em Salónica a 21 de janeiro de 1568. Para além da morte Amato Lusitano viveu nas referências temporais múltiplas feitas à sua vida e obra, transcendendo as coordenadas do espaço e do tempo em que viveu.

\section{CONFLITO DE INTERESSES}

A autora declara que não houve conflito de interesses na realização deste trabalho.

\section{FONTES DE FINANCIAMENTO}

A autora declara a inexistência de fontes de financiamento externas.

6. Dias JL. Iconographic memento on Amatus Lusitanus (1511-1568). [s.I.: s.n., D.L. 1968].

7. Laços Familiares de Amato Lusitano e Filipe Montalto: Novas investigações. Lisboa: Imprensa Médica; 1961.

8. Amato Lusitano: lusitano e europeu. Lisboa: Imprensa Médica; 1956.

9. Ricon-Ferraz A. Western medicine in the East: Amato Lusitano's Scientific and Clinical Experience. [s.l:sn]; 2002.

10. Pina L. Amato Lusitano: na História da Psiquiatria Portuguesa. Coimbra: Imprensa de Coimbra; 1955.

11. João Rodrigues de Castelo Branco, Amato Lusitano: resumo biobibliográfico. Lisboa: [s.n.]; 1952. 